PULSE

\section{The hazards of nursing}

A staggering $18 \%$ of 18348 Canadian nurses responding to a recent survey say their patients were "occasionally" or "frequently" administered the wrong medication or dose while in their care, according the first National Survey of the Work and Health of Nurses.

On the other side of the coin, nurses themselves are more likely to suffer injury, stress-related health problems, or experience emotional abuse from patients, according to the findings of the survey, the largest and most comprehensive ever undertaken on nurses' working conditions, and physical and mental health.

Some $29 \%$ of the respondents indicated that they' $\mathrm{d}$ been physically assaulted by a patient in the year 2005, while $44 \%$ said they'd been subjected to emotional abuse. The survey, a joint initiative of the Canadian Institute of Health Information, Statistics Canada, and Health Canada, saw roughly I9 000 of the nation's 3 I4 900 employed nurses interviewed about their work environment and health.

Equally surprising were survey findings related to quality of care, including medication mishaps and other adverse events such as infections originating from a hospital or health care setting.

According to the survey, patients are most likely to receive the wrong medication, or the wrong dose of a medication, in a long-term care facility (22.8\%), as opposed to $19.2 \%$ in hospitals (Table I). There was also a significant variation in the regional distribution of reported medication errors, from a high of $27.5 \%$ in Quebec, to a low of $6.5 \%$ in Newfoundland and Labrador. The remaining provinces fell within the $\mathrm{I} 2.4 \%-\mathrm{I} 7.5 \%$ range.

Quebec nurses also reported a higher incidence of patient infections originating within the hospital or health care setting in which they were employed. A phenomenal $42 \%$ of Quebec nurses say there was occasional or frequent nosocomial infection in their patients, slightly above the national average of $35.2 \%$. The national average rose to $39.5 \%$ in a hospital setting, as compared to $36 \%$ in a long-term care facility, I5. $1 \%$ in community health clinics, or $17.9 \%$ in other settings (e.g., physicians' offices, private nursing agencies, etc.).

Roughly one-third of nurses said their patients were injured in a fall in 2005 , ranging from a high of $63.4 \%$ in long-term care facilities and $26.1 \%$ in hospitals, to $15.4 \%$ in community health settings and $17.4 \%$ in other settings.

Some $8.9 \%$ of nurses said they were injured while working during 2005, including $10.6 \%$ in hospitals and $9.6 \%$ in long-term care facilities. That tally rose to a high of $12.3 \%$ in British Columbia.

The latter were among a number of findings indicating that nursing is be- coming one of the nation's most hazardous professions. Those findings included ones indicating that $48 \%$ of nurses suffered a needle-stick or cut on the job; $29 \%$ were physically assaulted; $44 \%$ were subjected to emotional abuse by patients or families of patients; $25 \%$ suffered chronic back problems; and $9 \%$ suffered from depression.

Canadian Nurses Association President Marlene Smadu says the report does a remarkable job of illustrating the impact of institutional and psychosocial factors, such as staff shortages and excessive workload, on mental and physical health.

The high incidence of adverse events is consistent with research indicating that "with every additional patient that a registered nurse has above what was considered to be an appropriate level, they could predict the increases in patient falls, patient infection rates, failure to rescue situations, you know, where someone is going downhill and that isn't picked up early enough," Smadu said.

Smadu argues that the findings also illustrate the need for a national action plan "to improve the quality of the workplace" in health care settings, as well as some form of national agency, similar to the National Patient Safety Institute, to serve as a clearinghouse of evidence-based best practices. Wayne Kondro, CMAJ

DOI:I0.I503/cmaj.06I704

Table 1: Adverse events reported by 15174 nurses providing direct care, by work setting, Canada, 2005

Event in past 12 mo that occurred occasionally or frequently; \% of nurses*

\begin{tabular}{lcccc}
\cline { 2 - 4 } Work setting & $\begin{array}{c}\text { Patient received } \\
\text { wrong medication } \\
\text { or dose }\end{array}$ & $\begin{array}{c}\text { Complaint from } \\
\text { patient or family } \\
\text { members }\end{array}$ & $\begin{array}{c}\text { Patient injured } \\
\text { in fall }\end{array}$ & $\begin{array}{c}\text { Reporting nurse } \\
\text { injured while } \\
\text { working }\end{array}$ \\
\hline Hospital & 19.2 & 39.9 & 26.1 & 10.6 \\
Long-term care facility & 22.8 & 50.7 & 63.4 & 9.6 \\
\hline Community health setting & 7.8 & 23.5 & 15.4 & 3.6 \\
\hline Othert & 9.3 & 23.2 & 17.4 & $2.8 \neq$ \\
\hline All & 17.9 & 38.3 & 31.0 & 8.9 \\
\hline
\end{tabular}

Source: 2005 National Survey of the Work and Health of Nurses, Statistics Canada.

*Tan cells = significantly higher percentage than estimated for the other categories of nurses in the group combined $(p<0.05)$. Green cells $=$ significantly lower percentage than estimated for the other categories of nurses in the group combined $(p<0.05)$.

†Includes physicians' offices, private nursing agencies, educational institutions, governments and associations.

$\neq$ Coefficient of variation between $16.6 \%$ and $33.3 \%$ (interpret with caution). 